\title{
Haynes 242 Alloy for LARES 2 Satellite
}

\author{
D. Pilone, A. Brotzu, F. Felli \\ DICMA, Sapienza Università di Roma, Via Eudossiana 18, 00184 Roma, Italy \\ daniela.pilone@uniroma1.it, andrea.brotzu@uniroma1.it,ferdinando.felli@uniroma1.it
}

\section{Ciufolini}

Dipartimento di Ingegneria dell'Innovazione, Università del Salento, Via per Monteroni, 73100 Lecce, Italy ignazio.ciufolini@gmail.com

\section{B. Negri}

Agenzia Spariale Italiana, Italy

barbara.negri@asi.it

\section{Paris}

Centro Ricerche Enrico Fermi, Via Panisperna 89/ A, 00184 Roma, Italy

claudio.paris@.cref.it

\begin{abstract}
The satellite LARES 2 is designed to test dragging of inertial frames, or frame-dragging, predicted by Einstein's theory of General Relativity, with accuracy of a few parts in a thousand. For this purpose, besides the typical requirements for a space construction, a high density alloy must be used. In this paper are reported the studies performed on a nickel alloy, the Haynes 242, that is considered a possible candidate for manufacturing all the metallic parts of LARES 2 and other passive geodetic satellites. Haynes 242 density and mechanical properties are compliant with the requirements of the mission. Three different casting with the nominal composition of the alloy have been prepared and tested along with a commercial bar of Haynes 242. The results of tensile and hardness tests on several specimens with different aging time are reported, along with the relevant metallographic analysis. Furthermore, a test on the machinability, performed on a screw, which is the most demanding item from the manufacturing point of view, is reported.
\end{abstract}

KEYWORDS. Haynes 242; LARES 2; Mechanical properties; passive satellite.

\section{open Access}

Citation: Pilone, D., Brotsu, A., Felli, F., Ciufolini, I., Negri. B., Paris, C., Haynes 242 Alloy for Lares 2 Satellite, Frattura ed Integrità Strutturale, 56 (2021) 56-64.

Received: 08.01.2021

Accepted: 07.02.2021

Published: 01.04.2021

Copyright: (C) 2021 This is an open access article under the terms of the CC-BY 4.0, which permits unrestricted use, distribution, and reproduction in any medium, provided the original author and source are credited.

\section{INTRODUCTION}

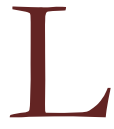

ARES 2 is a satellite of the Italian Space Agency (ASI), designed to test the dragging of inertial frames [1], or framedragging, an intriguing phenomenon predicted by Einstein's theory of General Relativity, with accuracy of a few parts in a thousand [2]. Frame-dragging has important implications in high energy astrophysics, the physics of black 
holes and gravitational waves detection. The satellite will also contribute to space geodesy and global climate monitoring similarly to what has been done with LARES satellite [3]. The main body of the satellite is made of one single piece of bulk metal. This type of design has been experimented the first time with LARES satellite [4]. The single piece design was chosen to reduce thermal gradients on the satellite and consequently the thermal thrust, a small but not negligible perturbation [5]. The satellite is completely passive, and it behaves as a test particle in the gravitational field of the Earth. It is covered with Cube Corner Reflectors (CCRs) that reflect the laser pulses sent from the network of ground stations of the International Laser Ranging Service (ILRS). The CCRs used for LARES 2 are smaller than the ones used for LARES and are Commercial Off The Shelf (COTS). By reconstructing its orbit with the laser ranging technique [6] it is possible to reach accuracies at the centimeter level or less. The LARES 2 mission has been designed aiming to an accuracy of one order of magnitude better than the one of LARES satellite. This goal can be achieved because of the special design of the satellite, its orbit, that must be supplementary to the one of the LAGEOS satellite, and the use of an updated gravitational field of Earth from GRACE and GRACE Follow-On missions [7-9]. The launch of LARES 2 is scheduled for 2021 with the qualification launch of VEGA C, an enhanced version of the VEGA launcher of the European Space Agency (ESA), and manufactured by an Avio-ASI joint venture. The main requirements for the structural material of the satellite are:

$\checkmark$ Physical: density of about $9000 \mathrm{~kg} / \mathrm{m}^{3}$, low sensitivity to heating by irradiation, non-magnetic properties, high thermal conductivity.

$\checkmark$ Technological: good castability, good workability.

$\checkmark$ Mechanical: hardness higher than $28 \mathrm{HRC}(285 \mathrm{HV})$, yield strength higher than $517 \mathrm{MPa}$ and elastic modulus greater than $200 \mathrm{GPa}$.

The first requirement is a compromise between the radius of the satellite, that cannot be smaller than $0.2 \mathrm{~m}$, and the need to have the smallest surface-to-mass ratio. In fact, a radius smaller than $0.2 \mathrm{~m}$ would have not allowed to accommodate the 303 CCRs which have been considered an acceptable threshold for the strength of the reflected signal from the satellite. The non-gravitational perturbations are proportional to the surface-to-mass ratio, that therefore must be minimized. The non-gravitational perturbations cannot be modeled with the required accuracy and degrade the accuracy of the framedragging measurement. The second requirement is related to the manufacturing of the satellite. The third requirement concerns the contact between the four hemispherical heads of the arms of the separation system and the corresponding four hemispherical cavities manufactured at the equator of the satellite. In Fig. 1 two hemispherical cavities are indicated with the arrows while the darker cavity is manufactured to allow handling and transportation of the satellite.

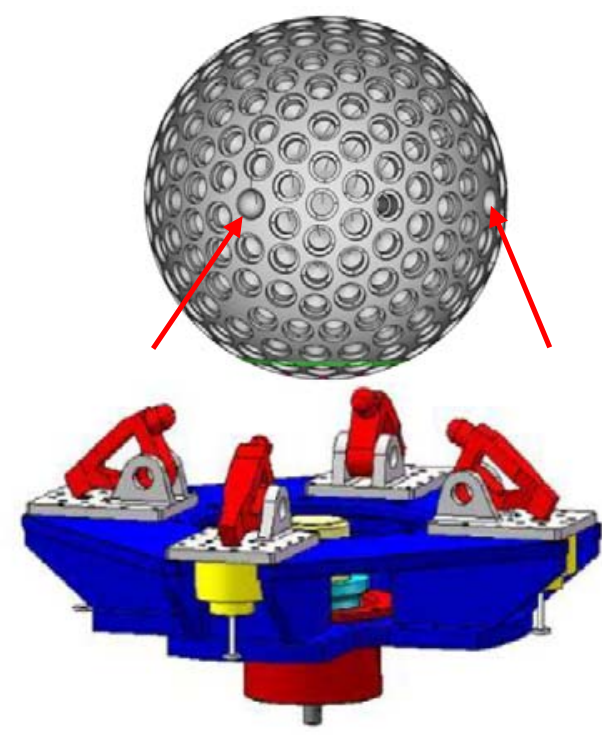

Figure 1: Rendered image of LARES 2 satellite and sketch of preliminary separation system [10].

The second and third requirements are induced by the pressure of the separation system on the satellite that is defined as a pre-load. This one is required to maintain the satellite in place during all the launch phases [11].

Based on these requirements, some copper and nickel-based alloys have been developed and analyzed. These alloys meet the above-mentioned physical requirements, but they have advantages and disadvantages. 
The copper-based alloys better meet the physical and the technological requirements but hardly reach the limit of the required mechanical properties; moreover, they change surface color due to oxidation during exposure to the air. The nickelbased alloys are more difficult to produce, have lower thermal conductivity, are more expensive but with significantly higher mechanical properties.

Different alloys of various compositions [12-14] have been produced and studied by analyzing microstructures, heat treatments, mechanical characteristics and workability. Important preliminary indications were obtained for a final choice of the alloy for the satellite, also bearing in mind all the problems related to the certifications required for new alloys to be used for a satellite to be launched with a rocket $[15,16]$.

The construction of the satellite involves the production of a spherical component of about $0.40 \mathrm{~m}$ in diameter. It is therefore necessary to evaluate the possible technologies that can be used (casting, forging, sintering, etc.). In particular, it is important to study which technology can be usefully applied to the different candidate alloys.

Among the alloys having mechanical properties close to the requirements the HAYNES ${ }^{\circledR} 242$ TM alloy is one of the most interesting [17-22]. This alloy was originally developed for applications in gas turbines. It is an alloy with very low thermal expansion and high resistance, even at high temperatures. It maintains good mechanical performances up to $760{ }^{\circ} \mathrm{C}$. The traditional heat treatment of the alloy leads to the formation of $\mathrm{Ni}_{2}(\mathrm{Mo}, \mathrm{Cr})$ precipitates having a size of about $10 \mathrm{~nm}$. Due to the formation of a large volumetric fraction of this phase, a great increase in the mechanical strength of the alloy is obtained.

Literature data suggest that the standard thermal treatment is aging at $650{ }^{\circ} \mathrm{C}$ for $24 \mathrm{~h}$.

A study was therefore carried out producing some demonstrative castings. Forging tests, machinability tests and mechanical tests were carried out on these castings to evaluate their potential, their characteristics and to verify whether they could be usefully used for the satellite production. Samples of commercial Haynes 242 alloy were also tested for comparison.

\section{EXPERIMENTAL}

$\mathrm{F}$ or the production of the specimens a Vacuum Induction Melting Furnace (VIM) was used. The first casting was produced by melting the alloy under vacuum and by casting the molten metal in a metallic mold. The second casting made under vacuum was poured into a ceramic mold and was characterized by the presence of big shrinkage cavities. For that reason, the metallic mold was preferred in this experimental work. The third casting was obtained by casting the molten metal, after fusion in air, in a metallic mold. The production of the castings under vacuum is divided into two phases. First, nickel was inserted into the crucible and molten inside the furnace at about $1455^{\circ} \mathrm{C}$. After about 7 minutes, a temperature of $1480{ }^{\circ} \mathrm{C}$ was reached and the alloying elements were added: molybdenum, chromium, silicon, manganese and aluminum. About 10 minutes were required to obtain the complete fusion of all elements. When the temperature reached $1420^{\circ} \mathrm{C}$ the alloy was cast. The production of the casting in air required the same procedure.

In addition to the three ingots described above, a commercial hot rolled bar was purchased from Haynes International. The solubilization treatment conducted on the specimens produced from the three ingots and the rolled bar, as well as on the forged material, that will be discussed below, is the standard treatment $[17,20]$. The solubilization treatment was carried out at $1100{ }^{\circ} \mathrm{C}$ for 1 hour and the subsequent cooling was carried out in air. The aging of the specimens was performed at 650 ${ }^{\circ} \mathrm{C}$ for $24 \mathrm{~h}, 48 \mathrm{~h}, 120 \mathrm{~h}$ and $144 \mathrm{~h}$. The specimens were subjected to metallographic characterization and to mechanical tests to observe the variations induced by the heat treatment. Metallographic analyses were performed after electrochemical etching carried out at $6 \mathrm{~V}$ by using a solution of $1 \mathrm{~g}$ of oxalic acid in $20 \mathrm{ml}$ of hydrochloric acid. Some specimens were produced from the ingot poured under vacuum, cast in a ceramic mold and subjected to hot forging. Forging was performed after bringing the casting to a temperature of $1150^{\circ} \mathrm{C}$ for $2 \mathrm{~h}$ : the obtained deformation was about $15 \%$.

Tensile tests were carried out for determining tensile strength, yield stress and elongation. Tensile test specimens were cut from the three ingots, the commercial bar and the forged material described above; they were $8 \mathrm{~mm}$ large, $3 \mathrm{~mm}$ thick and they had a gauge length of $30 \mathrm{~mm}$. Machinability tests have been carried out by producing screws.

\section{RESULTS AND DISCUSSION}

he compositional characterization of the samples by means of SEM-EDS allowed the determination of the composition of the specimens produced.

Tests were carried out on various samples taken from the three produced castings (Tab. 1). The alloy density was measured by using several specimens and the resulting mean value was $9,1 \mathrm{~g} / \mathrm{cm}^{3}$. 
The electrochemical etching revealed the dendritic structure of the alloy (Fig 1). Optical images in Fig. 2 highlights the presence of fine precipitates in the interdendritic areas. These precipitates are $\mathrm{Ni}_{2} \mathrm{Mo}$ e $\mathrm{Ni}_{2} \mathrm{Cr}$. Samples subjected to forging and aging have been also analyzed to identify their microstructure. As it can be seen in Fig. 3 the dendritic structure disappeared and a fine microstructure formed.

\begin{tabular}{ccccccccc}
\hline & Ni & Mo & Cr & Fe & Co & Si & Al \\
Nom. Comp. & Bal. & 25 & 8 & 2 max & 1 max & 0.8 max & 0.5 max \\
Casting 1 & 64.75 & 26.63 & 7.75 & 0.46 & 0 & 0.27 & 0.15 \\
Casting 2 & 65.39 & 26.15 & 8.05 & 0.38 & 0 & 0 & 0 \\
Casting 3 & 65.1 & 25.9 & 8 & 0.5 & 0.12 & 0 \\
\hline
\end{tabular}

Table 1: Mean composition of the 3 castings. Casting 1 was cast in vacuum in a metallic mould. Casting 2 was cast in vacuum in a ceramic mould. Casting 3 was cast in air in a metallic mould.
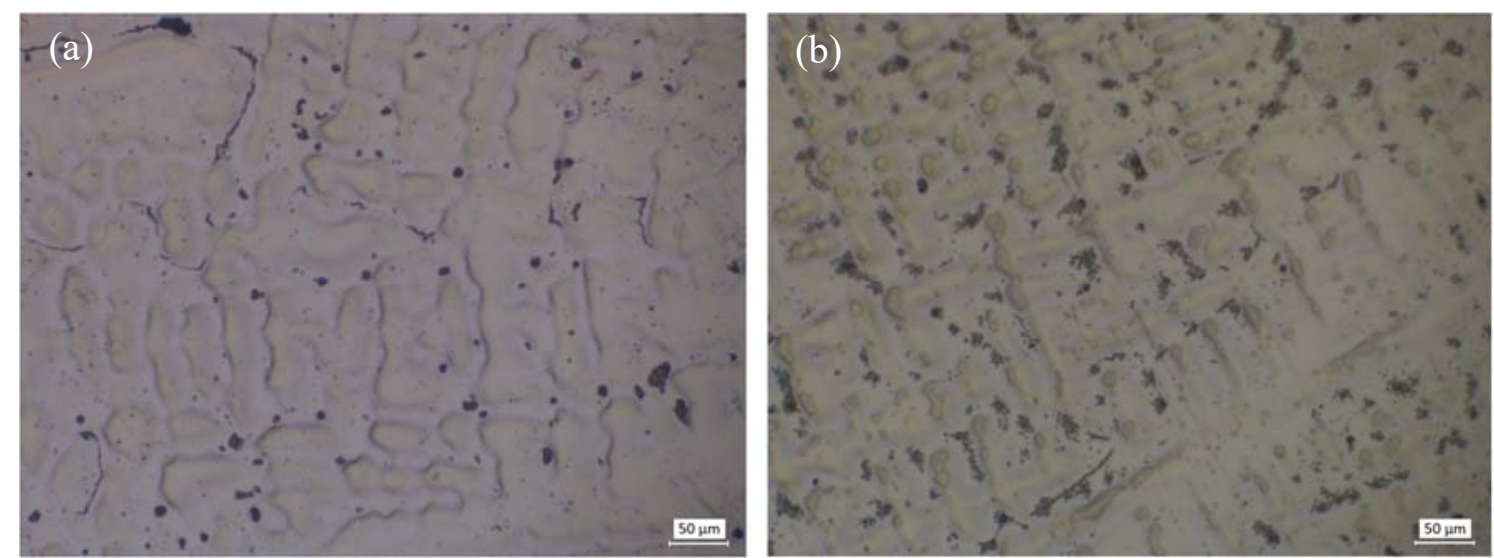

Figure 2: Optical micrographs showing the alloy microstructure in the as-cast condition (a) and after solubilization (b).

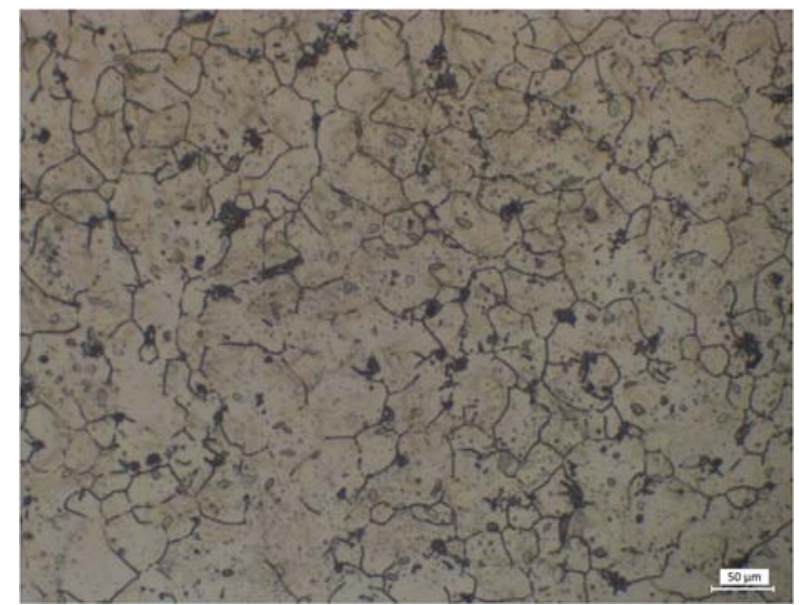

Figure 3: Optical image showing the alloy microstructure after forging and aging at $650{ }^{\circ} \mathrm{C}$ for $24 \mathrm{~h}$.

Considering that the mechanical properties of these alloys can be increased by performing aging treatment, aging tests have been performed on the as-cast, on the forged and on the commercial alloys. Fig. 4 shows the obtained results. In all the considered cases the mechanical properties increase is due to the precipitation of fine and dispersed particles of $\mathrm{Ni}_{2} \mathrm{Mo}$ e $\mathrm{Ni}_{2} \mathrm{Cr}$. 
The results show that in the solubilized state the commercial alloy has a slightly higher hardness. By performing aging treatment at $650^{\circ} \mathrm{C}$ the as-cast alloy increases its hardness, reaches a maximum after $48 \mathrm{~h}$ and then there is an overaging phenomenon. The forged alloy behavior is characterized by a hardness increase with time and it reaches 387 HV10 after $120 \mathrm{~h}$. This is probably due to the formation of fine grains that allows a more dispersed precipitate distribution. The commercial alloy shows a hardness that is slightly higher in comparison with the others; this may be ascribable to a structure that is more homogeneous in comparison with that of the as-cast material.

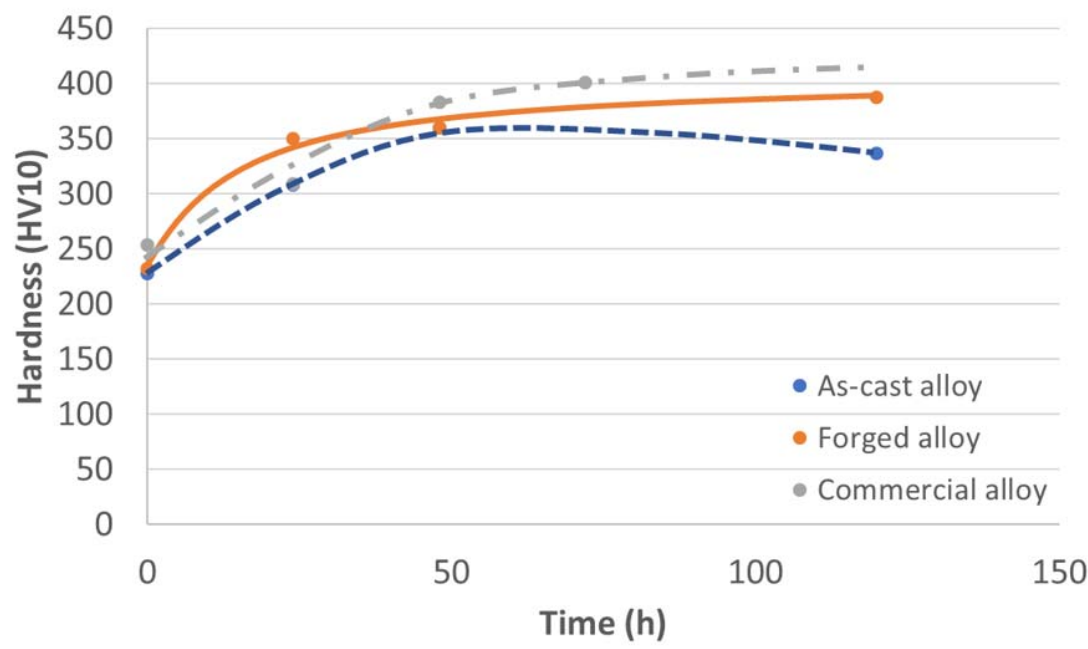

Figure 4: Aging curves showing the hardness of the as-cast, forged and commercial alloys as a function of aging time.

\begin{tabular}{|c|c|c|c|c|c|c|}
\hline & & $\begin{array}{c}\text { Vickers } \\
\text { Hardness } \\
\text { (HV10) }\end{array}$ & $\begin{array}{c}\text { Rockwell } \\
\text { Hardness } \\
\text { (HRC) }\end{array}$ & $\begin{array}{l}\text { Yield Stress } \\
\quad(\mathrm{MPa})\end{array}$ & $\begin{array}{l}\text { Ultimate tensile } \\
\text { strength }(\mathrm{MPa})\end{array}$ & Elongation (\%) \\
\hline \multirow{5}{*}{$\begin{array}{l}\text { Cast under } \\
\text { vacuum }\end{array}$} & As-Cast & 270 & 26 & 340 & 522 & 26 \\
\hline & Solubilized & 228 & 20 & 320 & 625 & 46 \\
\hline & Aged 24h & 308 & 32 & 450 & 596 & 16 \\
\hline & Aged 48h & 360 & 38 & 490 & 630 & 12 \\
\hline & Aged $120 \mathrm{~h}$ & 336 & 35 & 532 & 855 & 25 \\
\hline \multirow{4}{*}{ Forged } & Solubilized & 232 & 21 & 345 & 638 & 31 \\
\hline & Aged 24h & 350 & 37 & 580 & 907 & 22 \\
\hline & Aged 48h & 360 & 38 & 570 & 761 & 11 \\
\hline & Aged $144 \mathrm{~h}$ & 387 & 40 & 641 & 913 & 16 \\
\hline Commercial & Aged 24h & 309 & 32 & 720 & 1190 & 33 \\
\hline Alloy & Aged 48h & 383 & 40 & 747 & 1210 & 31 \\
\hline \multirow{2}{*}{ Cast in air } & Aged 24h & 297 & 30 & 520 & 593 & 10 \\
\hline & Aged $120 \mathrm{~h}$ & 336 & 35 & 610 & 704 & 11 \\
\hline
\end{tabular}

Table 2: Mechanical properties of the tested specimens. 
The results of the tensile tests are summarized in Tab. 2 for various castings both in the as-cast and in the forged state after heat treatment. The results obtained for the commercial alloy are also reported for comparison. For all the castings, even in the forged state, the obtained mechanical properties are lower than the ones characterizing the commercial alloy, but they abundantly meet the design requirements. As far as the differences with the commercial alloy are concerned, we can make the following considerations. The commercial alloy has been forged and drawn in the form of a bar, undergoing significant plastic deformations, while for the satellite we need to produce a sphere. It is being assessed whether to produce it by casting or by casting and forging, but with low deformations. Our study considered different types of castings whose properties meet the physical and mechanical requirements. It is apparent that forging treatment with a $15 \%$ reduction improves the mechanical properties of the alloy and that casting mechanical behavior is affected by the presence of microshrinkage cavities that decrease strength and toughness of the alloy as well as its density. By examining the behavior of the samples, we can observe that as the aging time increases, the mechanical strength increases and the ductility decreases and then increases again after 120 hours treatment. The alloy cast in air is generally less ductile.

Some significant $\sigma-\varepsilon$ curves characterizing the forged alloy (Fig. 5) are reported and compared with the one of the commercial alloy (Fig. 6). For all the tested specimens the plastic behavior is tendentially linear with a work hardening exponent of about 0.24 .

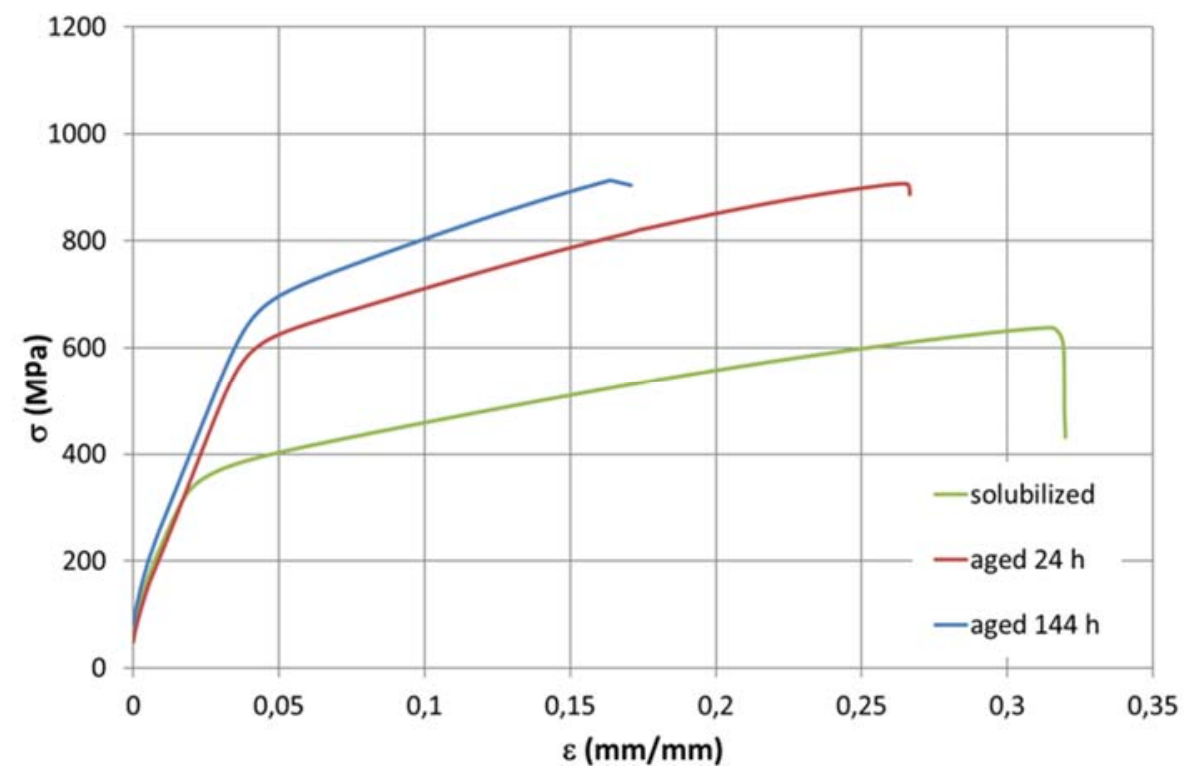

Figure 5: Stress-strain curves of the forged Haynes 242 alloy after solubilization and heat treatment.

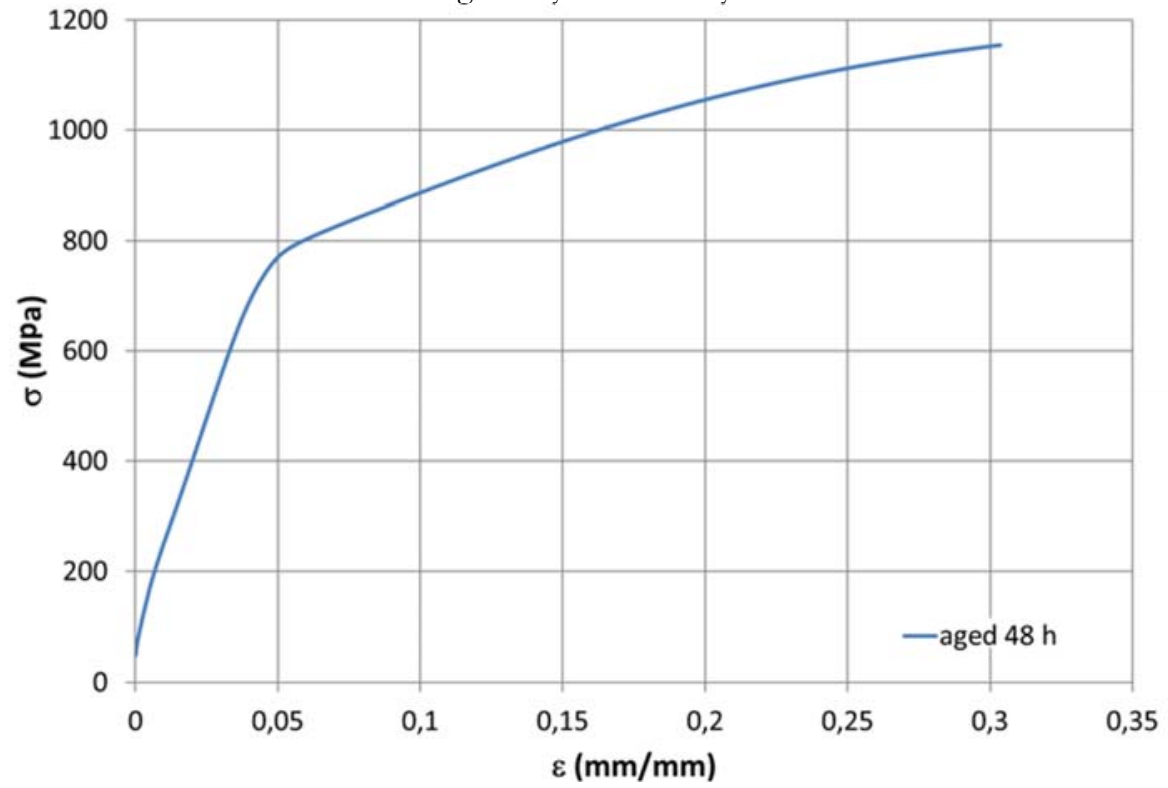

Figure 6: Stress-strain curve of the commercial Haynes 242 alloy aged for $48 \mathrm{~h}$. 

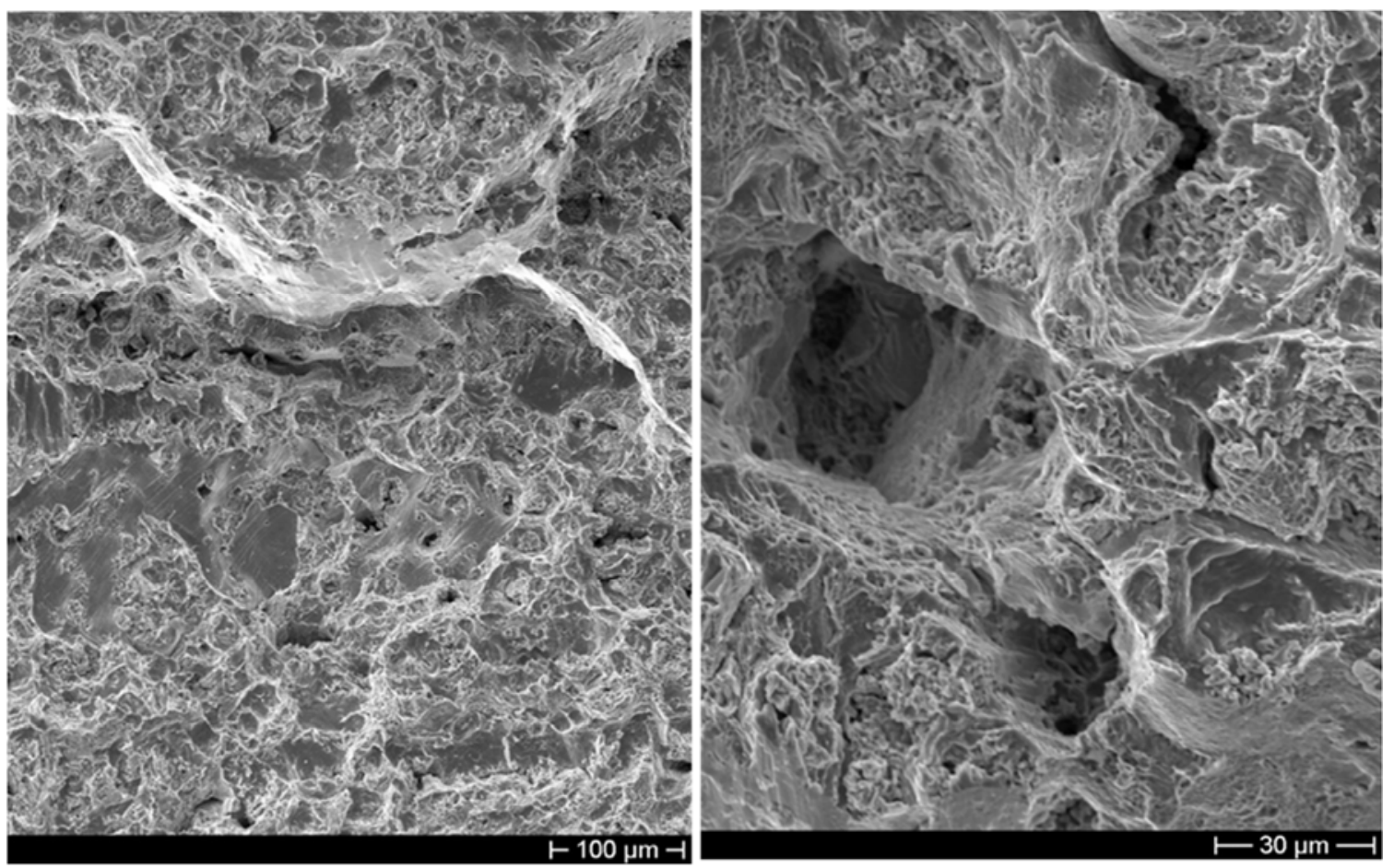

Figure 7: SEM micrograph showing the surface morphology of Haynes 242 aged at $650{ }^{\circ} \mathrm{C}$ for $24 \mathrm{~h}$.
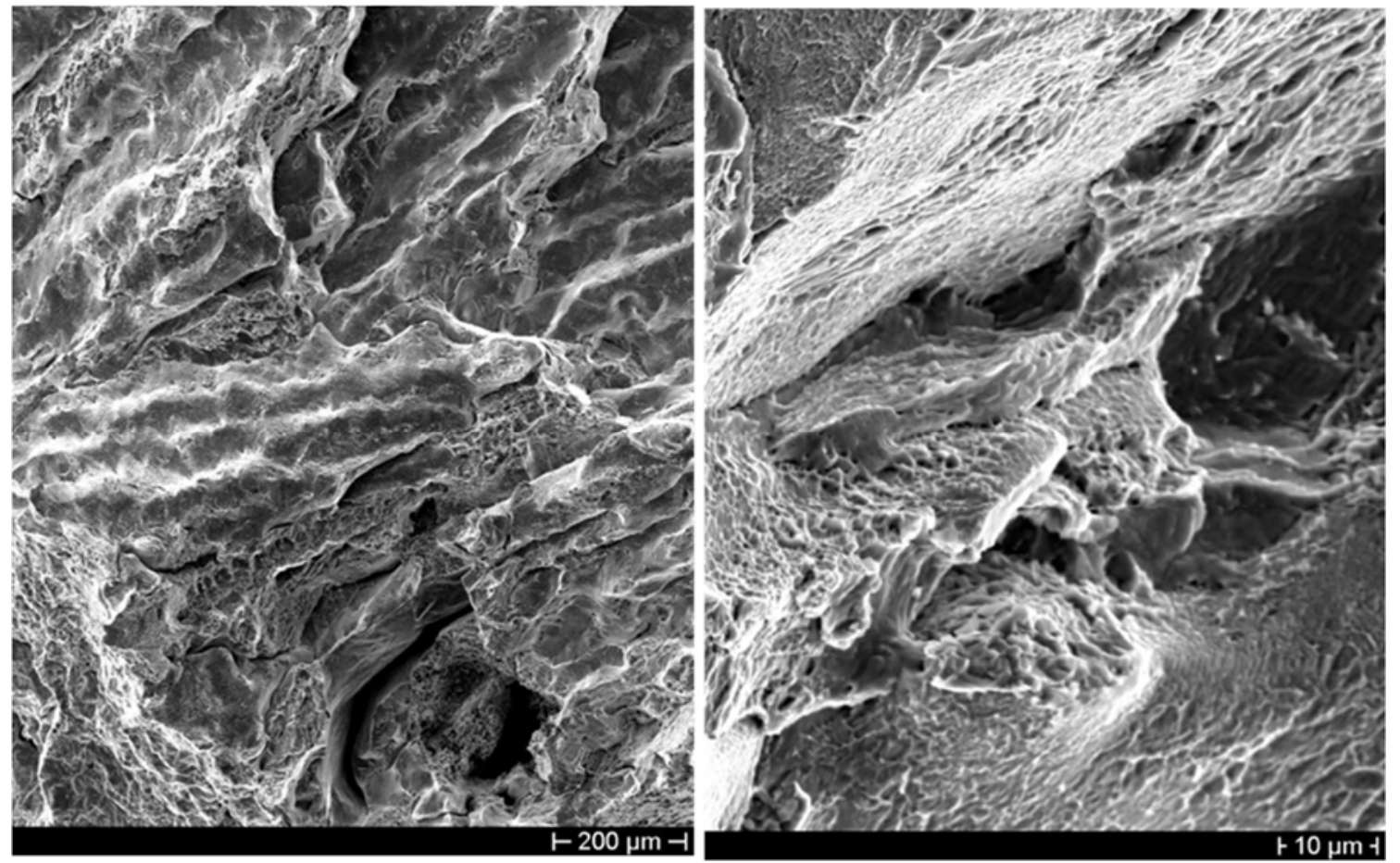

Figure 8: SEM micrograph showing the surface morphology of Haynes 242 aged at $650{ }^{\circ} \mathrm{C}$ for $120 \mathrm{~h}$.

After carrying out several tensile tests, observations of the fracture surfaces were performed by means of SEM. The observations were carried out on specimens aged for $24 \mathrm{~h}$ and $120 \mathrm{~h}$.

SEM micrographs of the sample aged for $24 \mathrm{~h}$ reveal at low magnifications that it is a ductile fracture (Fig. 7), while at higher magnifications the coexistence of areas with dimples, typical of ductile fractures, and areas of cleavage fracture is apparent. 
SEM micrographs of the alloy aged for $120 \mathrm{~h}$ (Fig. 8) highlight that, although the fracture appears prevalently ductile, the fracture morphology is a mixed mode fracture due to the presence of small areas characterized by a brittle behavior. After carrying out the mechanical tests, it was also necessary to evaluate the machinability of this alloy. This occurred through the production of screws. SEM analyses allowed to inspect the screw surface in order to evaluate any presence of superficial defects. SEM analyses showed that the alloy has a very good machinability even after aging. In fact, no defects are observable on the surface of the screws (Fig. 9).

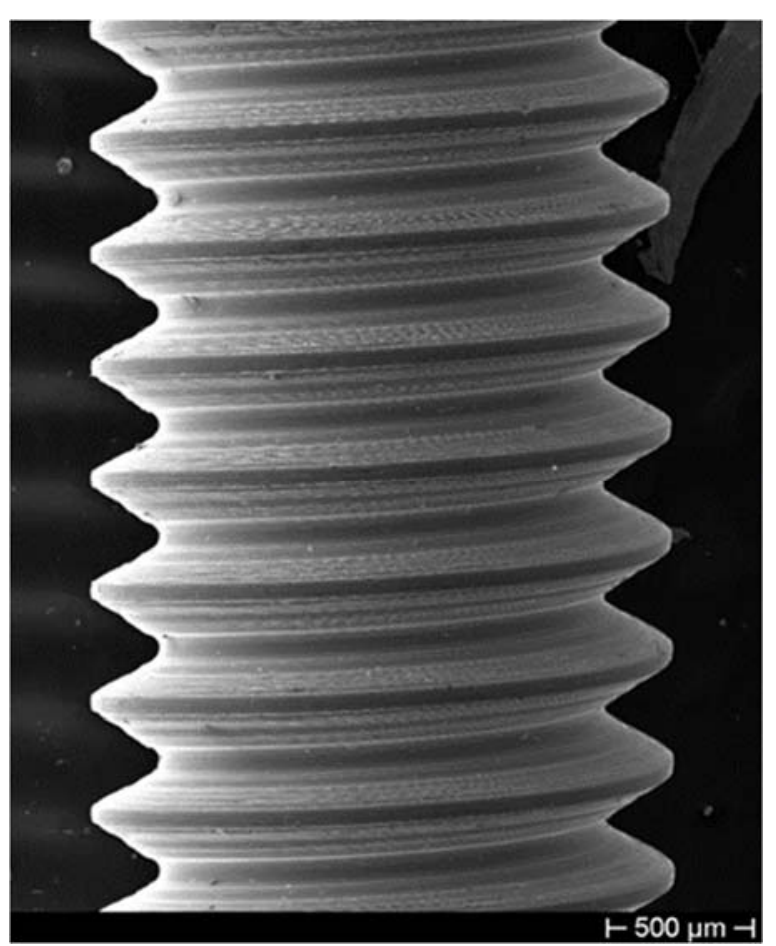

Figure 9: SEM micrograph showing the surface of a screw produced with Haynes 242 alloy aged for $24 \mathrm{~h}$.

\section{CONCLUSIONS}

I $\mathrm{n}$ this work Haynes 242 alloy has been considered as a possible candidate for the production of LARES 2 and similar satellites that may be launched in the future. Three different castings with the nominal composition of Haynes 242 have been produced and tested along with a commercial bar of Haynes 242. The results highlighted that the best results in terms of mechanical behavior were the ones relative to the commercial alloy that has been subjected to hot rolling. This thermomechanical treatment is not applicable to the satellite constituted by a metallic sphere, but it has been considered to substitute hot rolling with forging that will produce similar improvements to the mechanical characteristics. So on the ground of the obtained results the best process solution is casting, followed by forging that allows to optimize the alloy mechanical properties. However, the results show that even in absence of forging the aging is sufficient to fulfil the mechanical requirements. Haynes 242, although considered the optimal solution, and in fact was considered the baseline for the project, could not be selected because the procuring time was not compatible with the launch date of LARES 2.

\section{ACKNOWLEDGMENT}

7 he authors acknowledge the Italian Space Agency (ASI) for supporting the LARES and LARES 2 missions under agreements n. 2020-7-HH.0 and n. 2017-23-H.0. 


\section{REFERENCES}

[1] Ciufolini, I. (2007). Dragging of inertial frames. Nature, 449 (7158), pp. 41-47. DOI: 10.1038/nature06071.

[2] Ciufolini, I., Paolozzi, A., Pavlis, E.C. et al. (2017). A new laser-ranged satellite for General Relativity and space geodesy: I. An introduction to the LARES 2 space experiment. Eur. Phys. J. Plus 132, 336. DOI: 10.1140/epip/i2017-11635-1.

[3] Sindoni, G., Paris, C., Vendittozzi, C., Pavlis, E.C., Ciufolini, I., Paolozzi, A. (2015). The contribution of Lares to global climate change studies with geodetic satellites, (2015) ASME 2015 Conference on Smart Materials, Adaptive Structures and Intelligent Systems, SMASIS 2015, 2. DOI: 10.1115/SMASIS2015-8924.

[4] Paolozzi, A., Ciufolini, I., Paris, C., Sindoni, G. (2015). LARES: A new satellite specifically designed for testing general relativity. Int J Aerospace Eng, 341384. DOI: 10.1155/2015/341384.

[5] Ciufolini, I., Paolozzi, A. Paris, C., Sindoni, G. (2014). The LARES satellite and its minimization of the thermal forces, 2014 IEEE International Workshop on Metrology for Aerospace (MetroAeroSpace), May 29-30, 2014, Benevento, ITALY.

[6] Pavlis, E.C., Paolozzi, A., Paris, C., Ciufolini, I., Sindoni, G. (2015). Quality assessment of LARES satellite ranging data: LARES contribution for improving the terrestrial reference frame (2015) 2nd IEEE International Workshop on Metrology for Aerospace, MetroAeroSpace 2015 - Proceedings, art. No. 7180616, 1-5.

DOI: 10.1109/MetroAeroSpace.2015.7180616.

[7] Dahle, C., Murböck, M., Flechtner, F., Dobslaw, H., Michalak, G., Neumayer, K.H., Abrykosov, O., Reinhold, A., König, R., Sulzbach, R., and Förste, C. (2019). The GFZ GRACE RL06 Monthly Gravity Field Time Series: Processing Details and Quality Assessment. Remote Sensing, 11(18), 2116. DOI:10.3390/rs11182116.

[8] Dahle, C., Flechtner, F., Gruber, C., König, D., König, R., Michalak, G., and Neumayer, K.-H. (2014). GFZ RL05: An Improved Time-Series of Monthly GRACE Gravity Field Solutions. In Flechtner, F., Sneeuw, N., and Schuh, W.-D. (editors), Observation of the System Earth from Space - CHAMP, GRACE, GOCE and future missions, 29-40, Springer, Berlin, Heidelberg.

[9] Kornfeld, R.P., Arnold, B.W., Gross, M.A., Dahya, N.T., Klipstein, W.M., Gath, P.F., and Bettadpur, S. (2019). GRACE-FO: The Gravity Recovery and Climate Experiment Follow-On Mission. J Spacecraft Rockets, 56(3), pp. 931 951. DOI: 10.2514/1.A34326.

[10] Ciufolini, I., Paolozzi A., Pavlis E.C., Paris C., Sindoni G. (2019). LARES 2 an approved mission for testing general relativity, IAC-19-A2.1.4, 70th International Astronautical Congress, 21-25 Oct. 2019, Washington, D.C.

[11] Paris, C. (2015). Vibration tests on the preloaded LARES satellite and separation system, Aerosp Sci Technol, 42, pp. $470-476$

[12] Paolozzi, A., Sindoni, G., Felli, F., Pilone, D., Brotzu, A., Ciufolini, I., Pavlis, E.C., Paris, C. (2019). Studies on the materials of LARES 2 satellite. J Geodesy, 93 (11), pp. 2437-2446. DOI: 10.1007/s00190-019-01316-z.

[13] Brotzu, A., Felli, F., Pilone, D., Di Cocco, V., Sindoni, G., Ciufolini, I. (2019). Study of CuCrZr alloy for the production of a passive satellite, Procedia Structural Integrity, 18, pp. 742-748. DOI: 10.1016/j.prostr.2019.08.222.

[14] Felli, F., Brotzu, A., Pilone, D., Paolozzi, A., Ciufolini, I. (2018). Fracture behaviour of alloys for a new laser ranged satellite, Procedia Structural Integrity, 9, pp. 295-302. DOI: 10.1016/j.prostr.2018.06.026.

[15] ECSS-Q-ST-70-71C Rev.1 - Materials, processes and their data selection (15 October 2019), ECSS Secretariat, ESAESTEC Requirements \& Standards Division, Noordwijk, The Netherlands

[16] ECSS-Q-ST-70C Rev.2 - Materials, mechanical parts and processes (15 October 2019), CSS Secretariat, ESA-ESTEC Requirements \& Standards Division, Noordwijk, The Netherlands

[17] Gaurav, V., Jacinto Páramo Kañetas, P., Phanibhushana, M.V. (2018). Hot Deformation Characterization of Haynes242, Mater Today: Proc, 5 (11), pp. 25389-25395. DOI: 10.1016/j.matpr.2018.10.343.

[18] Stepniowska, E., Dymek, S. (2012), Structure-property relationship in a haynes ${ }^{\circledR} 242^{\mathrm{TM}}$ alloy subjected to long-term exposure at $650^{\circ} \mathrm{C}$, Sol St Phen, 186, pp. 156-159. DOI: 10.4028/www.scientific.net/SSP.186.156.

[19] Habeeb, H.H., Kadirgama, K., Noor, M.M., Rahman, M.M., Mohammad, B., Bakar, R.A., Abouel Hossein, K.A. (2010). Machining of nickel alloy 242 with cubic boron nitride tools, J Appl Sci, 10 (19), pp. 2322-2327.

[20] Dymek, S., Wróbel, M., Dollar, M., Blicharski, M. (2006). Influence of plastic deformation and prolonged ageing time on microstructure of a Haynes 242 alloy, J Microsc, 224 (1), pp. 24-26.

[21] Dymek, S., Dollar, M., Klarstrom, D.L. (1991). Strain hardening mechanisms in a NiMoCr alloy, Scripta Metall Mater, 25 (4), pp. 865-869.

[22] Rothman, M.F., Srivastava, S.K. (1993). Effect of cold work and aging upon the properties of a Ni-Io-Cr fastener alloy, J Eng Gas Turb Power, 115 (1), pp. 160-164. 